\title{
Circular DNA and DNA/RNA Hybrid Molecules as Scaffolds for Ricin Inhibitor Design
}

\author{
Matthew B. Sturm, Setu Roday, and Vern L. Schramm ${ }^{\star}$ \\ Department of Biochemistry, Albert Einstein College of Medicine, 1300 Morris Park Avenue, Bronx, \\ NY 10461, USA
}

\section{Abstract}

Ricin Toxin A-chain (RTA) catalyzes the hydrolytic depurination of $\mathrm{A}_{4324}$, the first adenosine of the GAGA tetra-loop portion of $28 \mathrm{~S}$ eukaryotic ribosomal RNA. Truncated stem-loop versions of the 28S rRNA are RTA substrates. Here, we investigate circular DNA and DNA/RNA hybrid GAGA sequence oligonucleotides as minimal substrates and inhibitor scaffolds for RTA catalysis. Closing the 5' - and 3'-ends of a d(GAGA) tetraloop creates a substrate with 92-fold more activity with RTA $\left(k_{\mathrm{cat}} / K_{\mathrm{m}}\right)$ than the $\mathrm{d}(\mathrm{GAGA})$ linear form. Circular substrates have catalytic rates $\left(k_{\mathrm{cat}}\right)$ comparable to and exceeding RNA and DNA stem-loop substrates, respectively. RTA inhibition into the nanomolar range has been achieved by introducing an N-benzyl-hydroxypyrrolidine (N-Bn) transition state analogue at the RTA depurination site in a circular GAGA motif. The RNA/DNA hybrid oligonucleotide cyclic GdAGA provides a new scaffold for RTA inhibitor design and cyclic $\mathrm{G}(\mathrm{N}-\mathrm{Bn}) \mathrm{GA}$ is the smallest tight-binding RTA inhibitor $\left(K_{\mathrm{i}}=70 \mathrm{nM}\right)$. The design of such molecules that lack the base-paired stem-loop architecture opens new chemical synthetic approaches to RTA inhibition.

\section{INTRODUCTION}

Ricin is a heterodimeric toxin abundant in castor beans. It is toxic by inhalation, oral, and intravenous exposure. ${ }^{1}$ Ricin Toxin A-chain (RTA) catalyzes the hydrolytic depurination of $\mathrm{A}_{4324}$, the first adenosine of the GAGA loop portion of $28 \mathrm{~S}$ eukaryotic ribosomal RNA. ${ }^{2}$ In the cell, depurination causes the loss of elongation factor binding, inhibition of protein synthesis, and cellular death. Ricin is infamous for its use as a bioterrorism agent, but has also been used as an anticancer agent via chimeric immunotoxin conjugates. ${ }^{3}$ Therapeutic uses of ricin immunotoxins have been limited by the vascular leak syndrome, a side effect resulting from inappropriate RTA targeting to the capillary beds, causing fluid escape to tissues including the lungs and brain. ${ }^{4,5}$ Thus, cancer therapies that employ an RTA-linked immunotoxin remain a challenge. An efficient antidote for RTA would provide a rescue therapy for normal cells following treatment of the target tumor tissue with immunotoxins. In addition, ricin is a class$\mathrm{B}$ biological hazard and inhibitors against its action may be useful as antidotes.

The $k_{\text {cat }}$ for RTA activity on rat liver ribosomes is $\sim 1800 \mathrm{~min}^{-1}$ with a $K_{\mathrm{m}}$ of $2.6 \mu \mathrm{M}$ at pH 7.6. ${ }^{6}$ In the absence of ribosomal proteins, RTA's hydrolytic rate is $0.07 \mathrm{~min}^{-1}$ with a similar binding affinity. ${ }^{6}$ The rates of hydrolysis for truncated $28 \mathrm{~S}$ stem-loop RNAs by RTA is slow at neutral pH. ${ }^{7-8}$ The catalysis and binding constants $\left(k_{\mathrm{cat}}\right.$ and $\left.K_{\mathrm{m}}\right)$ for 6 to 18 base stem-loop hairpins have been characterized at $\mathrm{pH} 4.0$ where catalysis is enhanced by the protonation of two ionizable residues on substrate or RTA (Figure 1). ${ }^{8-10}$ In these studies the most efficient RNA stem-loop is A-14 and is depurinated by RTA at $219 \mathrm{~min}^{-1}$ with a $K_{\mathrm{m}}$ of $8.1 \mu \mathrm{M}$. The

*Corresponding author: vern@aecom.yu.edu Telephone (718) 430-2813 Fax (718) 430-8565. 
catalytic hydrolysis of RNA GAGA tetraloop substrates is a function of stem length and a 500fold increase in catalytic turnover rate occurs as the number of base pairs in the stem are increased from 2 to $5 .{ }^{8}$ The turnover rate of stem-loop substrates without base paired stems was increased by cross-linking of the termini. ${ }^{11}$ Thus, stem formation is important in achieving the RTA transition state with RNA substrates. In DNA stem-loops, catalysis is 400-fold slower than A-14 RNA and stem length was shown to have no effect on catalysis. However, it functions to fold the tetraloop for RTA recognition. ${ }^{10}$ The $K_{\mathrm{m}}$ values of stable stem-loop RNA and DNA substrates are in the low micromolar range and change little as a function of stable stem length. Replacing deoxyribose for ribose bases in the GAGA tetraloop in RNA stem-loop substrates alters RTA binding and catalysis. ${ }^{9}$ Deletion of the $2^{\prime}-\mathrm{OH}$ in the second position of GAGA loop caused a 12 -fold increase in catalysis $\left(k_{\text {cat }}\right)$ with a similar 12 -fold decrease in binding affinity. The 2'-sugar hydroxyl is important for RTA recognition of the target adenosine in RNA stem-loops substrates while deoxyadenosine has a greater overall chemical reactivity towards depurination. ${ }^{9}$ Deoxyribose replacements for ribose bases in the 1, 2, or 4 position reduced catalysis up to 300 -fold with minor changes in $K_{\mathrm{m}}$.

Kinetic isotope effect studies established that RTA hydrolysis of RNA and DNA substrates occurs through leaving group activation via oxacarbenium ion transition states. ${ }^{12,13}$ Second generation inhibitors of RTA featured a) protonated 1-azasugars to mimic the oxacarbenium ion and b) leaving groups with elevated $\mathrm{p} K_{\mathrm{a}}$ values at the depurination site. ${ }^{14}$ RNA stem-loop substrate, A-10 (Figure 1) $\left(K_{\mathrm{m}}=2.9 \mu \mathrm{M}\right)$ has been used as a scaffold for inhibitor design to yield several nanomolar and micromolar transition state analogue inhibitors of RTA. However, inhibitors with free 5'- and 3'-ends are susceptible to degradation in biological systems and have large molecular weights. Thus, we sought an alternative inhibitor scaffold to the stemloop RNAs, in an effort to generate low molecular weight inhibitors that avoid degradation by exonucleases. ${ }^{15}$

Amukule et al. investigated minimal dimeric (GA) to tetrameric (GAGA) nucleotide substrates of RTA. ${ }^{10}$ These unstructured substrates had slower to negligible catalytic turnover and lower binding affinities than stem-loop DNA and RNA molecules (Table 1). Ricin A-chain prefers to act on structured stem-tetraloop substrates with the stem proposed to orient the GAGA tetraloop to provide an exposed adenine to permit RTA recognition and catalysis. ${ }^{16}$

We have produced minimal GAGA loops without the stem but where the tetraloop is closed at the 5'- and 3'-ends either by a covalent oxime linker or by a phosphorothioate bond (Figure 1). The selection of a 1-benzyl-aza sugar (N-Bn) as transition state analogue for cyclic inhibitors was based on previous work showing that RTA inhibition $\left(K_{\mathrm{i}}=99 \mathrm{nM}\right)$ occurs with $\mathrm{N}-\mathrm{Bn}$ at the depurination site of the A-10 stem-loop scaffold. ${ }^{14}$ Ricin catalysis and inhibition were tested with these novel circular oligonucleotides (Figure 1).

The cyclization of short oligonucleotides is entropically unfavorable. Several methods are available for the cyclization of oligonucleotides on solid support employing specific reactive group modifications to close the 5' to 3' nucleotide ends. ${ }^{17-19}$ Edupuganti et al. used a head to tail oxime cyclization for the synthesis of cyclic 3 to 11-mer DNAs using a 3'-glyceryl solid support and a synthetic 5 '-aminooxy phosphoramidite linker. ${ }^{17}$ This cyclization method provided yields up to $68 \%$ for cyclic DNA tetramers through standard $\beta$-cyanoethyl phosphoramidite automated synthesizer chemistry. Three circular DNA tetramer oligonucleotides (cyclic d(GAGA) (Figure 1), d[G(N-Bn)GA] and d[G(N-Bn)G(N-Bn)]) were synthesized using this method. To our knowledge, the synthesis of cyclic RNA and DNA/RNA hybrid molecules has not been previously reported with the oxime cyclization method. We synthesized two DNA/RNA hybrid molecules (cyclic GdAGA, and G(N-Bn)GA) utilizing a modification of this protocol. In the synthesis of directly closed cyclic oligonucleotides (ie. cyclic molecules without methylene spacers), we utilized a phosphorothioate cyclization 
method developed by Smietana et al. ${ }^{18}$ The yield with this method is reported to be up to $78 \%$ for dinucleotide phosphorothioates, although the efficiency is dependent on the identity of the 5'- terminal base. Solution cyclization occurs after the 5'-iodinated-3'-phosphorothiofunctionalized DNA oligonucleotide is deprotected from the solid support. Two tetramer DNA oligonucleotides (cyclic PS d(GAGA) (Figure1), d[G(N-Bn)G(7-deazaA)]) and dinucleotide cyclic PS d(GA) were synthesized employing this method.

Overall, cyclic DNA oligonucleotides are easier to chemically prepare because in RNA the 2'O-protections are an added complication. ${ }^{19}$

\section{MATERIALS AND METHODS}

\section{Materials}

Ricin Toxin-A chain (RTA) was purchased from Sigma. 3'-glyceryl CPG, 3'-phosphate CPG, nucleoside phosphoramidites and other DNA/RNA synthesis reagents were purchased from Glen Research (Sterling, VA) and ChemGene Co. (Ashland, MA). All other reagents were purchased at highest purity available from Aldrich Chemical Corp. (Ashland, MA) and used without additional purification. The 5 '-aminooxy phosphoramidite was chemically prepared as described by Forget. ${ }^{20}$ Intermediates in the synthesis of this phosphoramidite were purified on flash columns using Merck silica gel 60 (230-400 mesh) and identified by comparing NMR data to the published values. HPLC purifications were preformed on a Waters 626 pump with a 996 photodiode array detector with Millennium software. Oligonucleotide concentrations were determined by UV-Vis measurements using a Cary 100 diode array spectrophotometer.

\section{Preparation of oxime linked cyclic oligonucleotides}

Oligonucleotides were synthesized on a $1 \mu \mathrm{M}$ scale on 3'-glyceryl CPG support in the DMTon mode using an Expedite 8909 DNA/RNA synthesizer following standard synthesis protocols for $\beta$-cyanoethyl phosphoramidite chemistry. The terminal 5'-aminooxy phosphoramidite was incorporated with a 5 min coupling time. In our experience, 1 -aza sugar phosphoramidites are unstable and required immediate incorporation following synthesis. In synthesis of cyclic inhibitors, the crude DADMe N-benzyl sugar phosphoramidite (Scheme 1) was incorporated on the synthesizer with a 15 min coupling time. The trityl monitor confirmed that there was no reduction in the yield of the linear precursor using this approach. Cleavage and base deprotection of deoxynucleotides was accomplished in concentrated $\mathrm{NH}_{4} \mathrm{OH}\left(25^{\circ} \mathrm{C}\right.$ overnight). Deprotection of DNA/RNA-hybrids used 3:1 (v/v) $\mathrm{NH}_{4} \mathrm{OH} / \mathrm{EtOH}$ (at $55^{\circ} \mathrm{C}$ for 3 h). 2'-O-TBDMS deprotection of the RNA-hybrid was accomplished using $250 \mu \mathrm{L} / \mu$ mole of a TEA HF/NMP solution (1.5 mL N-methylpyrrolidine, $750 \mu \mathrm{L}$ TEA and $1.0 \mathrm{~mL}$ TEA-3HF) heated to $65^{\circ} \mathrm{C}$ for 2 hours. ${ }^{21}$ This reaction mixture was diluted with $2 \mathrm{~mL} / \mu$ mole of $0.5 \mathrm{M}$ $\mathrm{NH}_{4} \mathrm{OAc}$ and evaporated to dryness under vacuum.

Oxime-linked oligonucleotides were cyclized and purified following the steps outlined by Edupuganti et al. ${ }^{17}$ HPLC purification was accomplished to $>95 \%$ on a Waters Delta-Pak (7.9 $\mathrm{mm} \times 300 \mathrm{~mm}$ ) semi-preparative $\mathrm{C} 18$ reverse phase column at $3.5 \mathrm{~mL} / \mathrm{min}$. Unprotected precyclic oligonucleotides were purified in $20 \mathrm{mM} \mathrm{NH}_{4} \mathrm{OAc} / 5 \% \mathrm{CH}_{3} \mathrm{CN}$ with a linear $0-30 \%$ gradient of $\mathrm{CH}_{3} \mathrm{CN}$ in $20 \mathrm{~min}$. Final purification of cyclic tetramers to a single symmetric HPLC peak was accomplished with a 30 min $0-30 \% \mathrm{CH}_{3} \mathrm{CN}$ gradient. The masses of the final cyclic oligonucleotides were confirmed by MALDI-TOF mass spectrometry (supporting information). Samples were desalted on a C18 reverse phase Waters Sep-Pak cartridge according to the manufactures protocol and concentrated to dryness under vacuum. Oligonucleotides were resuspended in sterile RNAase free DEPC treated water and concentrations were determined by $\mathrm{UV}$ at $260 \mathrm{~nm}$ prior to enzymatic assays. 


\section{Preparation of phosphorothioate cyclic oligonucleotides}

Cyclic phosphorothioates were synthesized and purified according to the method of Smietana et al. ${ }^{18}$ HPLC purification was to $>95 \%$ purity on a Waters delta-pak $(7.9 \mathrm{~mm} \times 300 \mathrm{~mm})$ semi-preparative $\mathrm{C} 18$ reverse phase column at $2 \mathrm{~mL} / \mathrm{min}$ with a 30 minute gradient of 0-30\% $\mathrm{CH}_{3} \mathrm{CN}$ in $50 \mathrm{mM}$ triethyl ammonium acetate $\mathrm{pH}$ 7.0. MALDI analysis of the HPLC fractions was used to identify the desired molecule. Cyclic phosphorothioate oligonucleotides were evaporated to dryness in a speed vac concentrator and resuspended in sterile RNAase free water.

\section{Synthesis of N-Bn phosphoramidite}

4,4'-Dimethoxytrityl chloride ( $500 \mathrm{mg}, 1.49 \mathrm{mmol}$ ) was added portionwise to a solution of (3R,4R)-1-benzyl-4-(hydroxymethyl)pyrrolidin-3-ol (280 mg, $1.35 \mathrm{mmol})$ (1), Hunigs base $(1.0 \mathrm{~mL}, 5.7 \mathrm{mmol})$, and DMAP (30 $\mathrm{mg}$, catalytic) in anhydrous dichloromethane $(5 \mathrm{~mL})$ and the reaction left to stir at room temperature under argon. After $1 \mathrm{~h}$ the reaction was diluted with chloroform $(50 \mathrm{~mL})$, washed with water $(20 \mathrm{~mL})$, brine $(20 \mathrm{~mL})$, dried $\left(\mathrm{MgSO}_{4}\right)$ and concentrated in vacuo. Chromatography (ethyl acetate:petroleum ether 50:50 v/v) of the resulting residue afforded $82 \%(564 \mathrm{mg})(2)$ as a pale oil. $1 \mathrm{H} \mathrm{NMR}\left(\mathrm{CDCl}_{3}\right): \delta 7.35-6.70$ (m, 18H), $3.96(\mathrm{~m}, 1 \mathrm{H}), 3.68(\mathrm{~s}, 6 \mathrm{H}), 3.49(\mathrm{~m}, 2 \mathrm{H}), 3.03(\mathrm{~d}, \mathrm{~J}=7.2 \mathrm{~Hz}, 2 \mathrm{H}), 2.90(\mathrm{t}, \mathrm{J}=8.7$ $\mathrm{Hz}, 2 \mathrm{H}), 2.60(\mathrm{dd}, \mathrm{J}=9.9,2.9 \mathrm{~Hz}, 1 \mathrm{H}), 2.43(\mathrm{dd}, \mathrm{J}=9.9,5.6 \mathrm{~Hz}, 1 \mathrm{H}), 2.26(\mathrm{~m}, 1 \mathrm{H}), 2.01(\mathrm{~m}$, 1H). 13C NMR ( $\left.\mathrm{CDCl}_{3}\right)$ : $\delta 158.4,145.0,138.6,136.2,130.0,128.8,128.2,128.1,127.8,127.0$, $126.7,113.1,86.0,74.7,64.6,61.8,60.3,60.1,56.0,55.2,48.8 . \mathrm{C}_{33} \mathrm{H}_{36} \mathrm{NO}_{4}:\left(\mathrm{MH}^{+}\right)$: calc 510.2644. Found: 510.2624

Compound 2 (200 mg, 0.4 mmoles) and diisopropylammonium tetrazolide (67 mg, 0.4 mmoles) was dissolved in $5.5 \mathrm{~mL}$ anhydrous dichloromethane. 2-Cyanoethyl-tetraisopropylphosphoramidite $(0.18 \mathrm{~mL}, 0.57 \mathrm{mmoles})$ was added dropwise and the solution was stirred at room temperature under argon. TLC (ethyl acetate:petroleum ether 50:50 v/v with 5\% triethylamine) of the reaction showed complete conversion within $2 \mathrm{~h}$. The reaction was diluted with dichloromethane $(50 \mathrm{~mL})$, washed with water $(20 \mathrm{~mL})$, brine $(20 \mathrm{~mL})$, dried $\left(\mathrm{MgSO}_{4}\right)$ and concentrated in vacuo. N-Bn phosphoramidite (3) was afforded as a clear oil and used crude for DNA synthesis at an estimated $0.1 \mathrm{M}$ in anhydrous acetonitrile. ${ }^{31} \mathrm{P} \mathrm{NMR}\left(\mathrm{CDCl}_{3}\right)$ indicated formation of the phosphoramidite linkage with peaks at 148.7 and $149.4 \mathrm{ppm}$ for the phosphorous compound (3).

\section{RTA Kinetic Assay}

Catalytic assays: Varying concentrations of circular constructs were incubated at $37{ }^{\circ} \mathrm{C}$ in a solution containing RTA reaction buffer $(10 \mathrm{mM}$ potassium citrate and $1 \mathrm{mM}$ EDTA at $\mathrm{pH}$ 4.0) for 10 minutes. Reactions were initiated by the addition of RTA at concentrations typically less than $25 \mathrm{nM}$ to a total reaction volume of $100 \mu \mathrm{L}$. The solutions were quenched at timed intervals by the addition of $100 \mu \mathrm{L} 1 \mathrm{M}$ potassium phosphate ( $\mathrm{pH}$ 8.0). The samples were then injected onto a reverse-phase C18 Waters Delta-Pak analytical column $(3.9 \mathrm{~mm} \times 300 \mathrm{~mm})$ with isocratic elution in $50 \mathrm{mM}$ ammonium acetate (pH 5.0) containing $3 \%$ of $50 \%$ aqueous methanol, at a flow rate of $1 \mathrm{~mL} / \mathrm{min}$. The catalytic release of adenine was monitored at 260 $\mathrm{nm}$ and compared to a standard adenine concentration curve to calculate the quantity released during catalysis. Reaction times were varied to ensure that product formation was $<10 \%$ of the total substrate concentration. Adenine release per reaction time was used to determine the kinetic parameters for RTA on cyclic constructs. Initial rate kinetics were fit to the MichaelisMenten equation for the calculation of substrate $K_{\mathrm{m}}, k_{\mathrm{cat}}$ and $k_{\text {cat }} / K_{\mathrm{m}}$ values. 


\section{RTA Inhibition Assay}

Inhibition constants with circular molecules containing a DADMe N-benzyl (N-Bn) aza-sugar were determined using RNA A-10 $\left(k_{\mathrm{cat}}=4.1, K_{\mathrm{m}}=2.9 \mu \mathrm{M}\right)$ as the competitive substrate. In competitive inhibition assays, varying concentrations of circular G(N-Bn)GA, d[G(N-Bn)G $(\mathrm{N}-\mathrm{Bn})]$ and PS d[G(N-Bn)G(7-deazaA)] were pre-incubated with $25 \mathrm{nM}$ RTA for 10 minutes in reaction buffer at $37^{\circ} \mathrm{C}$. No adenine release was observed during this preincubation time. In a $100 \mu \mathrm{L}$ total volume, reactions were initiated by the addition of $7 \mu \mathrm{M}$ A-10. Inhibition assays with cyclic d[G(N-Bn)GA] did not include RTA pre-incubation step in order to avoid depurination of the deoxyadenosine base. Cyclic $\mathrm{d}[\mathrm{G}(\mathrm{N}-\mathrm{Bn}) \mathrm{GA}]$ was incubated with $7 \mu \mathrm{M}$ A10 in reaction buffer at $37^{\circ} \mathrm{C}$ for 10 minutes prior to the reactions initiation by RTA. In this reaction both substrate and inhibitor are catalyzed by RTA albeit A-10 is a 4-fold faster (Table 1). Reactions were quenched and adenine was quantified by the same HPLC method used in the catalysis assays. Values for the inhibition constant $\left(K_{\mathrm{i}}\right)$ were calculated by fitting the initial rates to the equation for competitive inhibition, $v=k_{\text {cat }}[\mathrm{S}] /\left[[\mathrm{S}]+K_{\mathrm{m}}\left(1+\mathrm{I} / K_{\mathrm{i}}\right)\right]$, where $v$ is the initial reaction rate, $[\mathrm{S}]$ is the substrate concentration, $K_{\mathrm{m}}$ is the Michaelis constant for A-10, and $k_{\text {cat }}$ is initial rate at A-10 saturation. Concentrations of inhibitor were kept $>5$ times that of enzyme concentration. In one case of tight inhibition, where the concentration of inhibitor was $\leq 5$ times enzyme concentration, a correction was made for free inhibitor concentration. The free inhibitor concentration was determined by the relationship $I=I_{\mathrm{t}}-\left(1-v_{\mathrm{i}} / v_{\mathrm{o}}\right) E_{\mathrm{t}}$, where $I_{\mathrm{t}}$ is total inhibitor concentration, $v_{\mathrm{i}}$ and $v_{\mathrm{o}}$ are the inhibited and uninhibited steady state rates, respectively, and $E_{\mathrm{t}}$ is the total enzyme concentration.

\section{MALDI Analysis of Oligonucleotides}

All cyclic products were identified using a MALDI-TOF mass spectrometer in the linear positive ion mode with external calibration. Samples were prepared on a 100 well gold plate by mixing $1 \mu \mathrm{L}$ of oligonucleotide $(\sim 100 \mu \mathrm{M})$ with $1 \mu \mathrm{L}$ matrix solution $(9: 1 \mathrm{of}: 50 \mathrm{mg} / \mathrm{mL} 3-$ hydroxypicolinic acid in $50 \%$ acetonitrile to $50 \mathrm{mg} / \mathrm{mL}$ ammonium citrate in $\mathrm{H}_{2} \mathrm{O}$ ). Observed and calculated masses for the final cyclic compounds are in supporting information .

\section{RESULTS AND DISCUSSION}

\section{Ricin Catalysis of Cyclic Substrates}

Circular DNA and DNA/RNA hybrid GAGA sequence oligonucleotides with unmodified bases were substrates for Ricin catalysis, including the dinucleotide cyclic PS d(GA) and all showed saturation kinetics (Figure 2). Interestingly, cyclic PS d(GA) is a substrate for RTA while the linear dinucleotide is not a substrate (Table 1). Cyclic d(GAGA) was depurinated by RTA 24-fold faster than the linear DNA tetra-nucleotide although both have similar binding constants $\left(K_{\mathrm{m}}\right)$. Transition state stabilization energies were calculated based on the Gibbs free energy relation $\Delta \mathrm{G}=-\mathrm{RT} \ln (\mathrm{K})$ where $\mathrm{K}$ is the ratio of catalytic turnover rates $\left(k_{\mathrm{cat}}\right)$ for related molecules. Cyclization of the DNA tetraloop decreased the barrier for transition state formation by $2.0 \mathrm{kcal} / \mathrm{mole}$. The 28 -fold increase in $k_{\mathrm{cat}} / K_{\mathrm{m}}$ for cyclic $\mathrm{d}(\mathrm{GAGA})$ with respect to the linear form is largely attributable to an increase in $k_{\text {cat }}$. The catalytic turnover rate of cyclic d(GAGA) exceeds that of dA12 [d(CGCGCGAGACGCG)], the optimum stem-loop DNA hairpin $\left(k_{\text {cat }}\right.$ $\left.=0.5 \mathrm{~min}^{-1}\right)$, by 13 fold. ${ }^{10}$ However, the $k_{\mathrm{cat}} / K_{\mathrm{m}}$ of cyclic $\mathrm{d}(\mathrm{GAGA})$ is similar to dA12 and other stem-loop DNA since stem binding improves the $K_{\mathrm{m}}$ of the latter. ${ }^{9}$

The $K_{\mathrm{m}}$ for cyclic PS d(GAGA), a closed tetraloop, is $46 \mu \mathrm{M}$, an enhancement of $\sim 2$-fold relative to cyclic d(GAGA) and the linear DNA sequence. Closing the tetraloop with a phosphorothioate bond gives this molecule a $0.5 \mathrm{kcal} / \mathrm{mole}$ advantage in binding energy relative to the oxime linked cyclic DNA. The catalytic turnover $\left(k_{\mathrm{cat}}\right)$ is 1.4-fold greater for PS $\mathrm{d}(\mathrm{GAGA})$ than for oxime linked d(GAGA) and the efficiency $\left(k_{\mathrm{cat}} / K_{\mathrm{m}}\right)$ is increased by 3 -fold. 
RTA catalysis of the DNA/RNA hybrid oxime linked cyclic GdAGA was 6-fold greater than the unstructured linear tetra-loop motif. Thus, the increased efficiency $\left(k_{\mathrm{cat}} / K_{\mathrm{m}}\right)$ of RTA on cyclic GdAGA is primarily due to the faster $k_{\text {cat }}$ (Table 1 ). Cyclization lowered the $K_{\mathrm{m}}$ by 1.7fold which represents a $-0.3 \mathrm{kcal} / \mathrm{mole}$ binding stabilization.

In stem-loop RNA and DNA substrates for RTA the large difference in catalytic efficiency is theorized to result from RNA achieving optimal interphosphate distances for RTA recognition.

${ }^{10}$ Simulated molecular docking of a 29-mer RNA stem-loop substrate in RTA shows favorable binding free energies for backbone phosphates in the tetraloop and two GC bases of the proximal stem. ${ }^{22}$ However, the majority of the stem nucleotides in stem-loops do not directly interact with RTA. The distance between the 5'- and 3'-end phosphates of the tetra-loop in the NMR structures of A-12 (Pdb 1ZIG) is 16 .23 Molecular dynamics with Hyperchem estimate that these distances are $\sim 15 \AA$ for oxime linked cyclic d(GAGA) and GdAGA (supporting information). In cyclic tetra-loop molecules the minimal loop-recognition elements are present for RTA substrate binding and catalysis, but the stem is missing. Despite this truncation, cyclic tetra-loops d(GAGA), PS d(GAGA), d[G(N-Bn)GA] and GdAGA all achieve $k_{\mathrm{cat}} / K_{\mathrm{m}}$ values within an order of magnitude from each other (Table 1). Although these are much better substrates than small linear nucleic acids, they are 2 to 3 orders of magnitude weaker substrates than A-14. The similar $k_{\mathrm{cat}} / K_{\mathrm{m}}$ values of these small loop structures suggest that the base-paired stem contributes $2-3 \mathrm{kcal} / \mathrm{mole}$ toward catalysis.

\section{RTA Second Site Depurination}

RTA has been reported to cleave the first adenine of the d(GAGA) tetraloop of stem-loop DNA-10mers (dA-10) 100-fold more efficiently than the second adenine site. ${ }^{13}$ With RNA stem-loops (A-10) specificity is absolute for the first adenine. ${ }^{8,13}$ In contrast, a palindromic sense of recognition by RTA of the cyclic d(GAGA) makes the efficient release of adenine from both sites possible. Indeed, both mono and di-base deadenylation products were observed by MALDI analysis of the cyclic d(GAGA) substrate hydrolytic reaction thus establishing RTA dual site depurination (see supporting information). It is evident from kinetic analysis that RTA depurinates adenosine in cyclic $\mathrm{d}[\mathrm{G}(\mathrm{N}-\mathrm{Bn}) \mathrm{GA}]$ with a $k_{\text {cat }}$ of $1.1 \mathrm{~min}^{-1}$ (Table 1). The kinetic parameters observed for cyclic $\mathrm{d}[\mathrm{G}(\mathrm{N}-\mathrm{Bn}) \mathrm{GA}]$ substrate catalysis are equivalent to cyclic GdAGA. Thus, second site depurination occurs with robust specificity for deoxyadenosine bases in both circular tetra-loop substrates of RTA (Table 1). In contrast, the second site adenosine in the RNA cyclic analogue $\mathrm{G}(\mathrm{N}-\mathrm{Bn}) \mathrm{GA}$ is not depurinated by RTA.

Cyclic $\mathrm{d}[\mathrm{G}(\mathrm{N}-\mathrm{Bn}) \mathrm{GA}]$ acts both as a slow substrate with release of second-site adenine and as an competitive inhibitor of A-10 stem-loop substrate hydrolysis by RTA (Table 1,2). The $K_{\mathrm{m}}$ values of substrates for RTA are known to be dissociation constants and $K_{\mathrm{i}}$ values for competitive inhibition are also dissociation constants. ${ }^{12,13}$ If binding as a substrate and inhibitor were the same for Cyclic d[G(N-Bn)GA] the apparent $K_{\mathrm{m}}$ would equal $K_{\mathrm{m}}(1+[\mathrm{I}] /$ $\left.K_{\mathrm{i}}\right)(25 \mu \mathrm{M})$ since inhibitory binding by the substrate competes with substrate binding in the productive mode. Thus, cyclic $\mathrm{d}[\mathrm{G}(\mathrm{N}-\mathrm{Bn}) \mathrm{GA}]$ binds in two distinct geometries with the second site adenine in the catalytic site in preparation for hydrolysis and the N-Bn group of the transition state analogue in the catalytic site for inhibition with an apparent dissociation constant of $2.7 \mu \mathrm{M}$ (Table 2).

\section{Ricin Inhibition with Cyclic d[G(N-Bn)GA]}

The competitive inhibition constants $\left(K_{\mathrm{i}}\right)$ calculated for cyclic inhibitors on RTA are shown in Table 2.

Cyclic d[G(N-Bn)GA] inhibits RTA with a $K_{\mathrm{i}}$ of $2.7 \mu \mathrm{M}$ (Figure $3 \mathrm{a}$ ) and is $\sim 3$-fold tighter than the most favorable stem-loop substrates (RNA A-14 and DNA dA-12) and 33-fold tighter than 
cyclic d(GAGA). The N-Bn transition state analogue at the depurination site contributes a 0.7 $\mathrm{kcal} / \mathrm{mole}$ gain in binding energy compared to $\mathrm{d}(\mathrm{GAGA})$. Initial rate inhibition assays with cyclic $\mathrm{d}[\mathrm{G}(\mathrm{N}-\mathrm{Bn}) \mathrm{G}(\mathrm{N}-\mathrm{Bn})]$ and $\mathrm{G}(\mathrm{N}-\mathrm{Bn}) \mathrm{GA}$ gave no inhibition when starting the reactions with the addition of RTA (Figure 3d). Preincubation trials at fixed concentrations indicated that five minutes were required for RTA to associate with these inhibitors (data not shown). When these circular oligonucleotides were pre-incubated with RTA, initial rate curves gave competitive inhibition with good curve fits (Figure 3b,c). No change in RTA activity was observed in control samples during this incubation time. In addition, no inhibitor depurination was observed for these inhibitors. Cyclic $\mathrm{d}[\mathrm{G}(\mathrm{N}-\mathrm{Bn}) \mathrm{G}(\mathrm{N}-\mathrm{Bn})]$ gained 2-fold in affinity $(0.5$ $\mathrm{kcal} / \mathrm{mole})$ for RTA relative to cyclic d[G(N-Bn)GA] with a $K_{\mathrm{i}}$ of $1.3 \mu \mathrm{M}$. This result is surprising because (N-Bn) in both depurination sites in cyclic $d[\mathrm{G}(\mathrm{N}-\mathrm{Bn}) \mathrm{G}(\mathrm{N}-\mathrm{Bn})]$ eliminates the adenines that contribute to tetra-loop structure, and yet they bind 2-fold tighter than RNA stem-loop A-10 substrate (Table 2).

RTA inhibition with cyclic G(N-Bn)GA gave a $K_{\mathrm{i}}$ value of $70 \mathrm{nM}$. Therefore, with the simple $\mathrm{N}$-Bn oxacarbenium-ion mimic, this molecule gains $3.9 \mathrm{kcal} / \mathrm{mole}$ in binding energy relative to its substrate counterpart, cyclic GdAGA. RTA inhibition with this cyclic G(N-Bn)GA is comparable to the tightest binding observed for a variety of RNA stem-loop 10-mer inhibitors. 14

Cyclic PS d[G(N-Bn)G(7deazaA)] was not a good RTA inhibitor with or without preincubation and did not inhibit RTA up to $10 \mu \mathrm{M}$ (data not shown). In this construct, 7-deaza-2'deoxyadenosine was incorporated in order to avoid fourth site depurination. Cyclic PS d[G(NBn)G(7deazaA)] was not a substrate for RTA and the 7-deaza-2'-deoxyA prevented favorable RTA recognition of the inhibitor.

NMR structural determinations of GAGA tetra-loops show a triple purine stack between the last 3 tetraloop bases and a G-A sheared base pair between the first and fourth positions of the loop. ${ }^{23}$ The 7 -aza of the second adenosine contributes to the sheared G-A base pair through a favorable hydrogen bond ( $2.5 \AA$ ) between the 2 -amino group of guanine and N7 of the second adenine. Thus, a disruption of this interaction likely influences tetraloop structure and RTA recognition.

\section{CONCLUSION}

Circular DNA and DNA/RNA oligonucleotides of the GAGA recognition sequence are efficiently deadenylated by RTA. The phosphorothioate closed DNA tetraloop, cyclic PS d (GAGA), had a $k_{\text {cat }} 33$-fold faster than linear d(GAGA) and 1.4-fold faster than the oxime linked circular d(GAGA). The rates of RTA hydrolysis on DNA cyclic tetramers were up to 18 -fold greater than all previously studies DNA stem-loops from 6-18-bases long. ${ }^{10}$ However, the $K_{\mathrm{m}}$ of cyclic substrates were 5 to 12 -fold higher than stem-loops. In stem-loop substrates, the stem folds the tetraloop for catalysis and proximal stem forms remote interactions with RTA for binding. In circular tetra-loops the linker constrains the tetra-loop in a favorable conformation for RTA catalysis. Dinucleotide cyclic PS d(GA) is a $0.6 \mathrm{~min}^{-1} \mathrm{RTA}$ substrate with a weak binding affinity while its linear form is catalyzed $\sim 1$ million times slower and does not bind. The $k_{\text {cat }}$ of this cyclic dinucleotide is faster than stem-loop DNA but the binding $\left(K_{\mathrm{m}}\right)$ is reduced 50-fold. RTA recognizes the circular DNA tetraloop in a palindromic fashion. In the catalytic site, RTA can bind the DNA circular oligonucleotide in either the $5^{\prime} \rightarrow 3$ ' or the $3^{\prime} \rightarrow 5^{\prime}$ mode. This is supported by the observation that cyclic $\mathrm{d}[\mathrm{G}(\mathrm{N}-\mathrm{Bn}) \mathrm{GA}]$ is a substrate as well as an inhibitor of RTA and cyclic $\mathrm{d}\left[\mathrm{G}(\mathrm{N}-\mathrm{Bn}) \mathrm{G}(\mathrm{N}-\mathrm{Bn})\right.$ binds $\left(K_{\mathrm{i}}\right) 2$-fold tighter.

Small circular DNA and DNA/RNA tetramers are promising scaffolds for RTA inhibitor design. A nanomolar inhibition constant has been shown here for one such circular 
oligonucleotide containing the RTA transition state analogue DADMe N-benzyl (N-Bn). The best inhibitor was cyclic G(N-Bn)GA with a $K_{\mathrm{i}}$ of $70 \mathrm{nM}$ making it the lowest molecular weight nanomolar inhibitor of RTA. The comparable N-Bn 10-mer stem-loop inhibitor has a $K_{\mathrm{i}}$ of 99 $\mathrm{nM}$ and the tightest RTA inhibition reported is $26 \mathrm{nM}$ for N-Bn 10-mer with deoxyguanosine adjacent to the 5 ' side of the depurination site (Table 2) ${ }^{14}$ Our results suggest that cyclic tetraloop nucleic acids can efficiently serve as scaffolds for RTA inhibitors, with binding similar to RNA stem-loop inhibitor constructs. Cyclic G(N-Bn)GA gains $3.9 \mathrm{kcal} / \mathrm{mol}$ in binding over its circular GdAGA substrate. Pre-incubation of RTA with cyclic oxime inhibitors prior to substrate addition was necessary for active inhibition. Since the RTA reaction does not require preincubation, the cyclic oxime inhibitors undergo a conformational rearrangement in the presence of RTA through the flexible six carbon methylene bridge in the 5' to 3' linker. Other combinations of ribo/deoxyribonucleosides in the circular tetraloop and leaving groups that more faithfully represent adenine at the transition state may increase binding affinity. Varied linker lengths may also alter base configurations, relative substrate catalytic efficiencies, and inhibitor binding affinities. Circular oligonucleotides hold promise as novel substrates and inhibitors of RTA.

\section{Supplementary Material}

Refer to Web version on PubMed Central for supplementary material.

\section{Acknowledgements}

This work was supported by NIH research grant CA72444. DADMe-N-Bn (1) was generously provided by Drs. G. B. Evans, P. C. Tyler and R. H. Furneaux of Industrial Research Ltd, New Zealand.

\section{References}

1. Franz DR, Jaax NK. Medical aspects of chemical and biological warfare. 1997;32:631-42.

2. Endo Y, Mitsui K, Motizuki M, Tsurugi K. J Biol Chem 1987;262(12):5908-12. [PubMed: 3571242]

3. Schnell R, Vitetta E, Schindler J, Barth S, Winkler U, Borchmann P, Hansmann ML, Diehl V, Ghetie V, Engert A. Leuk Lymphoma 1998;30:525-537. [PubMed: 9711915]

4. Baluna R, Rizo J, Gordon BE, Ghetie V, Vitetta ES. Proc Natl Acad Sci USA 1999;96:3957-62. [PubMed: 10097145]

5. Baluna R, Coleman E, Jones C, Ghetie V, Vitetta ES. Exp Cell Res 2000;258:417-424. [PubMed: 10896793]

6. Endo Y, Tsurugi K. J Biol Chem 1988;263:8735-39. [PubMed: 3288622]

7. Gluck A, Endo Y, Wool IG. J Mol Biol 1992;226(2):411-24. [PubMed: 1379305]

8. Chen XY, Link TM, Schramm VL. Biochemistry 1998;37:11605-13. [PubMed: 9708998]

9. Amukele TK, Schramm VL. Biochemistry 2004;43:4913-22. [PubMed: 15109249]

10. Amukele TK, Roday S, Schramm VL. Biochemistry 2005;44:4416-25. [PubMed: 15766271]

11. Allerson CR, Verdine GL. Chem Biol 1995;2(10):667-675. [PubMed: 9383473]

12. Chen XY, Berti PJ, Schramm VL. J Am Chem Soc 2000;122:1609-17.

13. Chen XY, Berti PJ, Schramm VL. J Am Chem Soc 2000;122:6527-34.

14. Roday S, Amukele T, Evans GB, Tyler PC, Furneaux RH, Schramm VL. Biochemistry 2004;43:492333. [PubMed: 15109250]

15. Lipinski CA, Lombardo F, Dominy BW, Feeney PJ. Adv Drug Delivery Rev 2001;46:3-26.

16. Olson MA. Proteins 1997;27:80-95. [PubMed: 9037714]

17. Edupuganti OP, Defrancq E, Dumy P. J Org Chem 2003;68:8708-10. [PubMed: 14575507]

18. Smietana M, Kool ET. Angew Chem Int Ed 2002;41:3704-7.

19. Micura R. Chem Eur J 1999;5(7):2077-82.

20. Forget D, Boturyn D, Defrancq E, Lhomme J, Dumy P. Chem Eur J 2001;7(18):3976-84. 
21. Wincott F, DiRenzo A, Shaffer C, Grimm S, Tracz D, Workman C, Sweedler D, Gonzalez C, Scaringe S, Usman N. Nucleic Acids Research 1995;23(14):2677-84. [PubMed: 7544462]

22. Olson MA, Cuff L. Biophys J 1999;76(1):28-39. [PubMed: 9876120]

23. Jucker FM, Heus HA, Yip PF, Moors EH, Pardi A. J Mol Biol 1996;264(5):968-80. [PubMed: 9000624] 


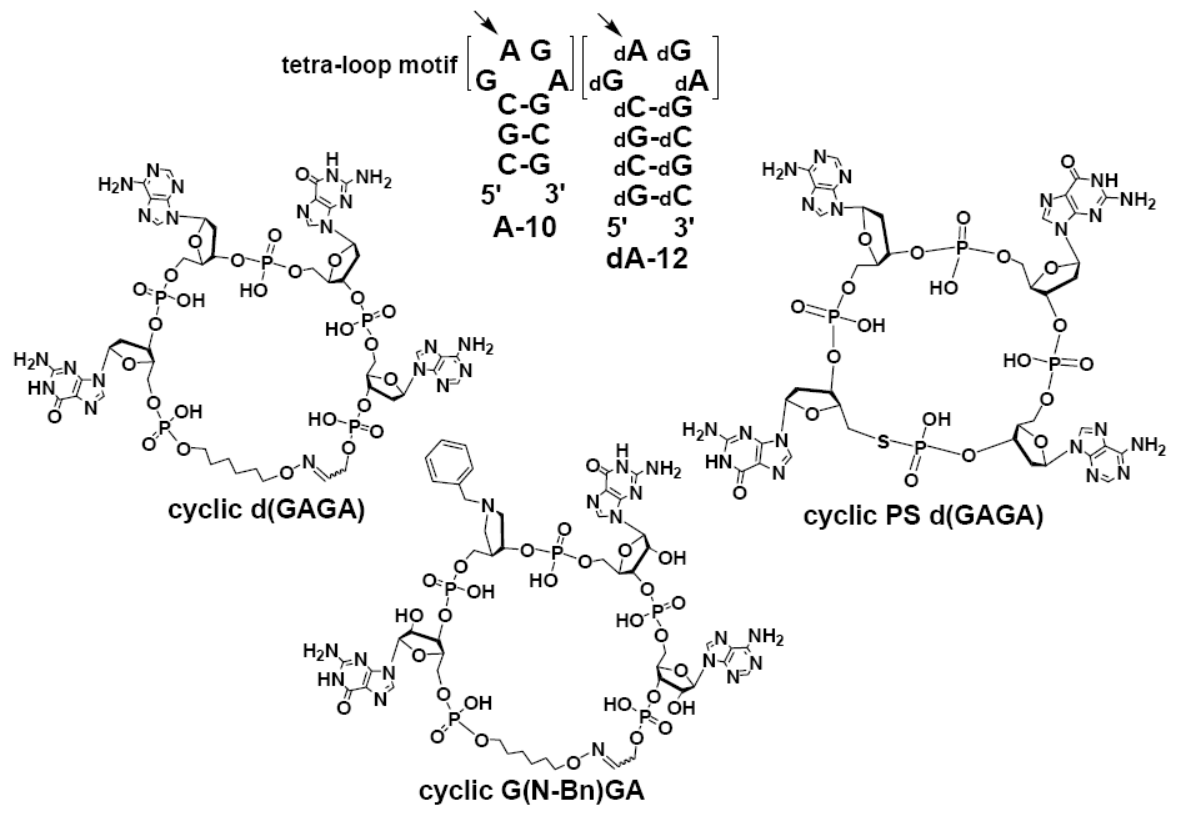

Figure 1.

Cyclic tetramers based on the RTA active site tetra-loop motif. A-10 and dA-12 are RNA and DNA stem-loop substrates respectively and are depicted with the tetra-loop in brackets with an arrow indicating the target adenosine. Circular DNA d(GAGA) and DNA/RNA hybrid G (N-Bn)GA are 5' - to 3'-synthetically linked by a six carbon methylene bridge and an oxime bond. Benzyl-1-aza-sugar (N-Bn) is a transition state analogue previously characterized in A-10 as a nanomolar RTA inhibitor. Cyclic PS d(GAGA) is a DNA GAGA sequence covalently closed at the 5' to 3'-ends by a phosphorothioate bond. 

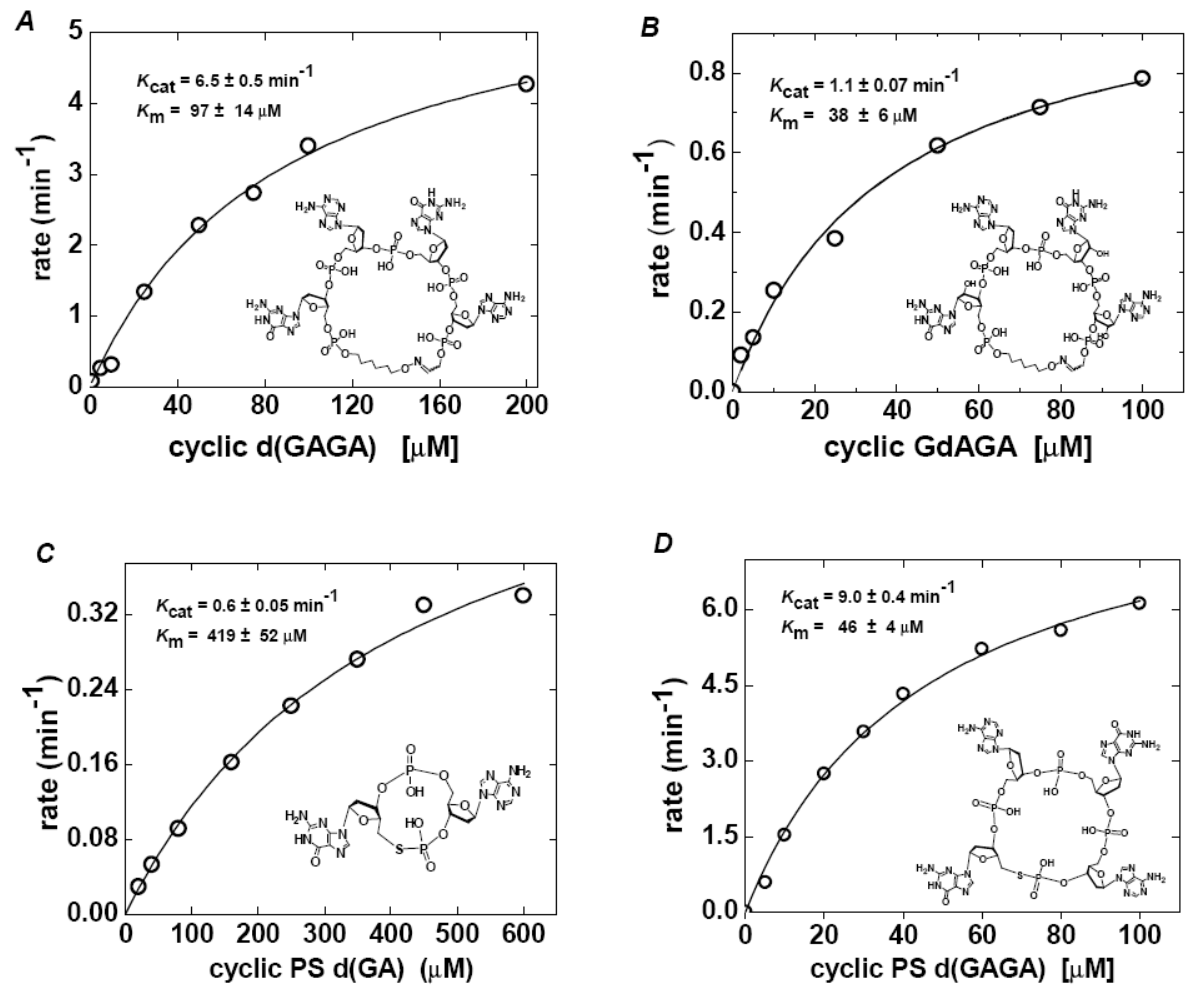

Figure 2.

Michaelis-Menten kinetic curve fits for cyclic d(GAGA) (A), cyclic GdAGA (B), cyclic PS d(GA) (C), and cyclic PS d(GAGA) (D) showing the rate of adenine release versus substrate concentration. The kinetic values are results from individual substrate experiments. 

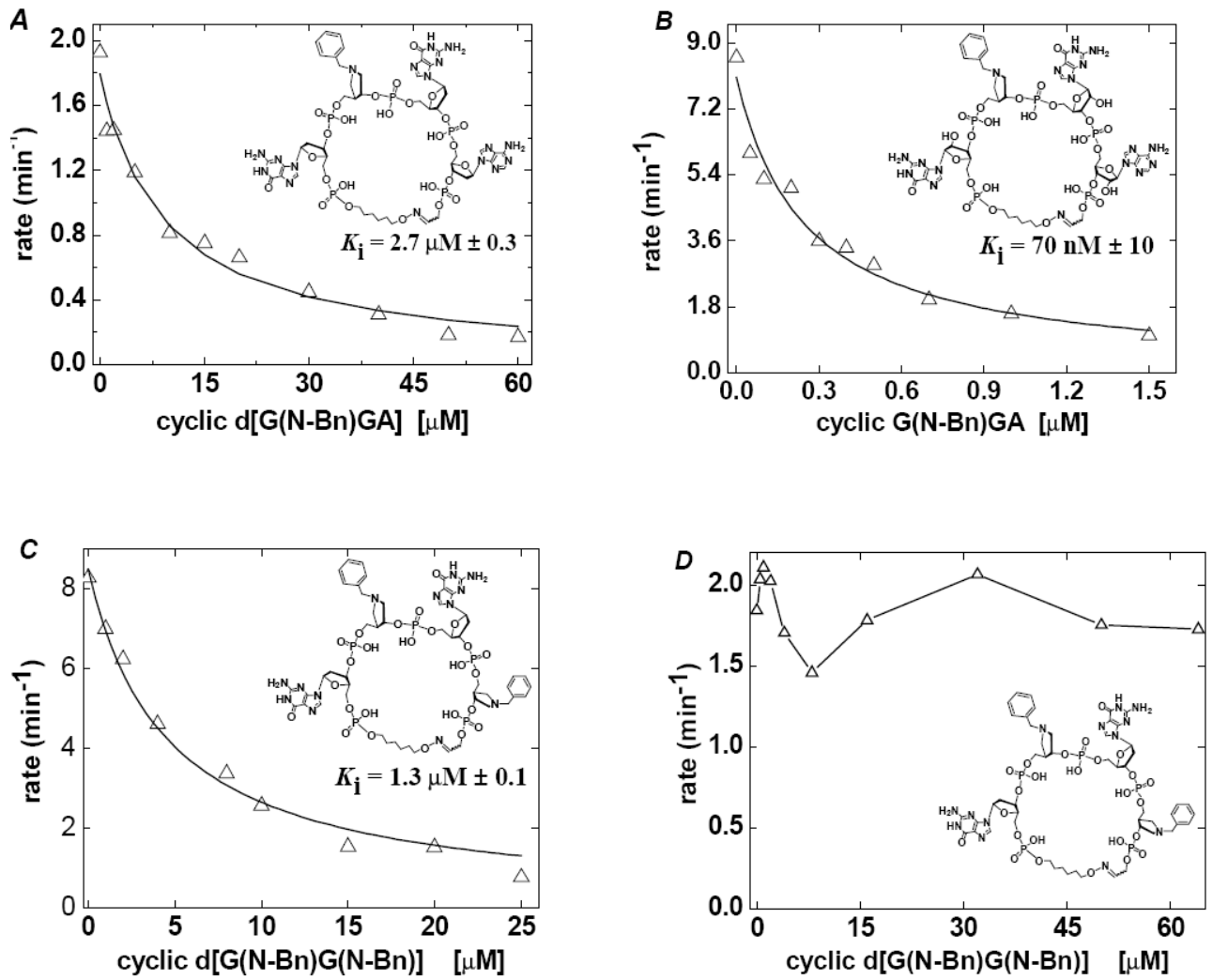

Figure 3.

Competitive inhibition of RTA as a function of circular inhibitor concentration with a fixed concentration of $7 \mu \mathrm{M}$ A-10 substrate. Curve fits for cyclic d[G(N-Bn)GA] (A), cyclic G(NBn)GA (B) are shown. Graph (C) and (D) represent curve fits for cyclic d[G(N-Bn)G(N-Bn)] inhibition with (C) and without (D) a 10 minute pre-incubation with RTA prior to assays, respectively. 


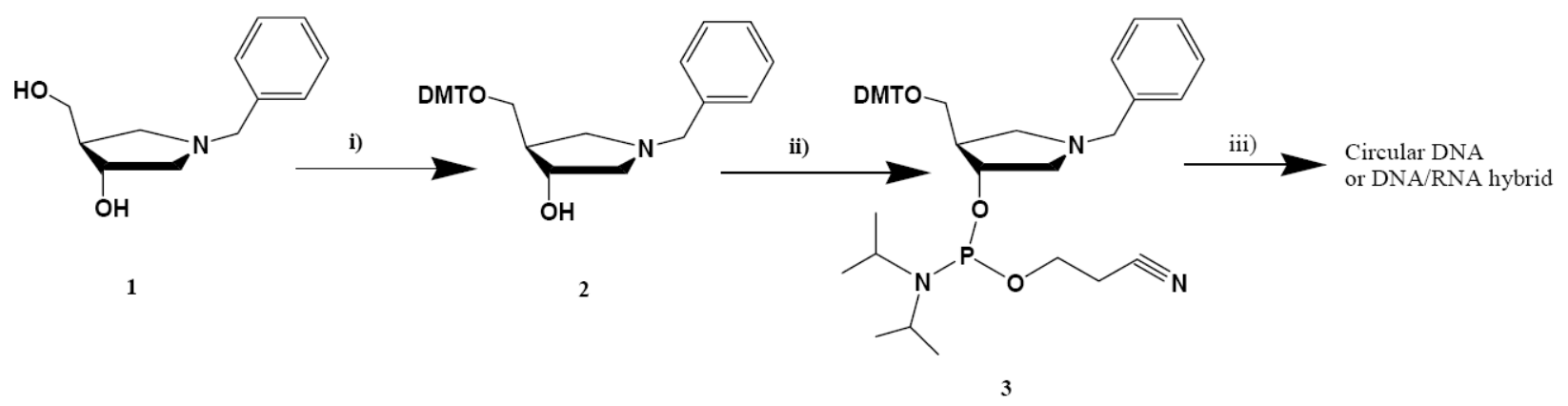

Scheme 1.

Synthesis of N-Bn phosphoramidite i) DMTCl (1.1 equiv), Hunigs base (4 equiv), DMAP (catalytic), methylene chloride, room temperature, 1 hour. ii) 2-Cyanoethyl-tetraisopropylphosphoramidite (1.4 equiv), tetrazole diisopropylammonium (1 equiv), methylene chloride, room temperature, 2 hours. iii) Solid support synthesis on Expedite 8909. 
Table 1

Kinetic parameters for circular substrates compared to linear forms with stem-loop DNA and RNA

\begin{tabular}{|c|c|c|c|}
\hline substrate & $k_{\mathrm{cat}}\left(\min ^{-1}\right)$ & $K_{\mathrm{m}}(\mu \mathrm{M})$ & $k_{\mathrm{cat}} / K_{\mathrm{m}}\left(\mathrm{M}^{-1} \mathrm{~s}^{-1}\right)$ \\
\hline $\mathrm{A}-14^{a}$ & $219 \pm 14$ & $8.1 \pm 0.7$ & $4.5 \times 10^{5}$ \\
\hline $\mathrm{dA}-12^{b}$ & $0.5 \pm 0.01$ & $8.4 \pm 1.2$ & $9.9 \times 10^{2}$ \\
\hline linear d(GAGA) $)^{b}$ & $0.27 \pm 0.04$ & $112 \pm 36$ & 40 \\
\hline cyclic d(GAGA) & $6.5 \pm 0.5$ & $97 \pm 14$ & $1.1 \times 10^{3}$ \\
\hline cyclic PS d(GAGA) & $9.0 \pm 0.4$ & $46 \pm 4$ & $3.2 \times 10^{3}$ \\
\hline cyclic $\mathrm{d}[\mathrm{G}(\mathrm{N}-\mathrm{Bn}) \mathrm{GA}]$ & $1.1 \pm 0.1^{c}$ & $39 \pm 10$ & $4.7 \times 10^{2}$ \\
\hline linear $\mathrm{GdAGA}^{b}$ & $0.18 \pm 0.03$ & $65 \pm 31$ & 62 \\
\hline cyclic GdAGA & $1.1 \pm 0.07$ & $38 \pm 6$ & $4.8 \times 10^{2}$ \\
\hline linear d(GA) $)^{b}$ & $<5 \times 10^{-5}$ & - & - \\
\hline Cyclic PS d(GA) & $0.60 \pm 0.05$ & $419 \pm 52$ & 24 \\
\hline
\end{tabular}

${ }^{a}$ An RNA stem-loop hairpin RTA substrate previously characterized (8)

$b$

DNA stem-loop dA-12 and linear GAGA, unstructured DNA and RNA/DNA substrates (10)

${ }^{c} k$ cat represents release of adenine from the fourth base in the tetraloop 
Table 2

Competitive inhibition constants for circular inhibitors compared to A-10 (substrate and N-Bn inhibitors)

\begin{tabular}{|c|c|}
\hline substrate & $\boldsymbol{K}_{\mathrm{i}}(\boldsymbol{\mu M})$ \\
\hline A-10 (substrate $)^{a}$ & $2.9\left(K_{\mathrm{m}}\right)$ \\
\hline $\mathrm{A}-10(\mathbf{N}-\mathrm{Bn})^{b}$ & 0.099 \\
\hline $\mathrm{A}-10$ 5-dG $(\mathbf{N}-\mathrm{Bn})^{b}$ & 0.026 \\
\hline cyclic G(N-Bn)GA $^{b}$ & $0.070 \pm 0.01$ \\
\hline cyclic d[G(N-Bn)GA] & $2.7 \pm 0.3$ \\
\hline cyclic d[G(N-Bn)G(N-Bn)] & $1.3 \pm 0.1$ \\
\hline Cvclic PS d[G(N-Bn)G(7deazaA)] & - \\
\hline
\end{tabular}

${ }^{a}$ An RNA stem-loop hairpin RTA substrate previously characterized (8)

$b$ Modified RNA stem-loop hairpin RTA inhibitor with the target adenosine replaced with 1-azasugar (N-Bn) (14) 